\title{
A privatização das águas no contexto da contrarreforma do Estado brasileiro
}

\author{
The privatization of water in the context \\ of the counter-reform of the Brazilian State
}

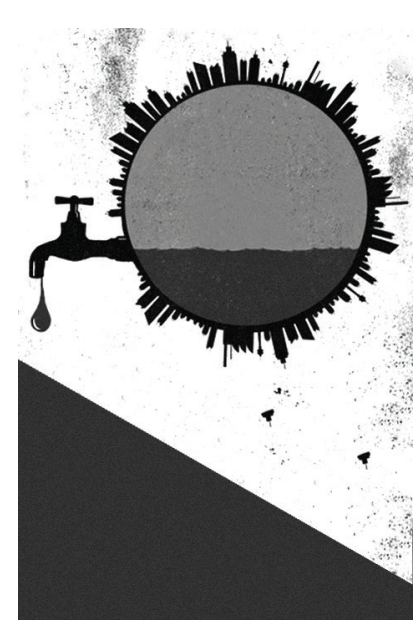

Josiane Soares Santos*
Yanne Angelim Acioly**

Resumo: O artigo problematiza a chamada reforma aquária no Brasil, proposta pelo governo federal destacando suas dimensões socioeconômicas e ambientais. Tal proposta pretende alterar as formas de controle do acesso à água com vistas à sua privatização já que este é um recurso natural que, além de essencial à preservação da vida, integra todos os processos de produção. Em função disso afirma-se que a reforma aquária se caracteriza como uma das ações da contrarreforma do Estado brasileiro conforme os interesses dominantes em busca da superação da atual crise do capital.

Palavras-chave: Crise do capital. Contrarreforma do Estado. Reforma aquária.

Abstract: The article brings forward the so-called water reform in Brazil, as it was proposed by the federal government. It highlights its social, economic and environmental dimensions. Such a proposal intends to change the ways of controlling the access to water, in view of its privatization, as water is a natural resource that integrates every process of production, besides the fact that it is essential to preserve life. Because of that, the water reform is considered one of the actions of the counter-reform of the Brazilian state, according to the dominant interests in search of getting over the present crisis of capital.

Keywords: Crisis of capital. Counter-reform of the state. Water reform.

* Graduada em Serviço Social pela Universidade Federal de Sergipe (UFS), professora adjunta do curso de graduação e da pós-graduação em Serviço Social da Universidade Federal de Sergipe (UFS), Aracaju (SE), Brasil, mestre e doutora em Serviço Social (UFRJ).E-mail: josisoares@hotmail.com.

** Graduada em Serviço Social pela Universidade Estadual do Ceará (Uece), professora assistente do curso de graduação em Serviço Social da Universidade Federal de Sergipe (UFS), Aracaju/SE, Brasil. Mestre em Políticas Públicas e Sociedade (Uece).E-mail: yanneufs@gmail.com. 


\section{Introdução}

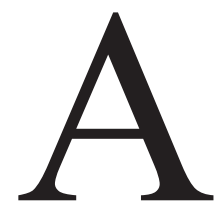

constatação do descompasso entre a exploração dos recursos da natureza e o tempo necessário à sua recomposição tem sido objeto de debate recorrente entre diversos atores, entre os quais, pesquisadores, movimentos sociais, Estado, setor empresarial e organizações internacionais, uma vez que põe em questão a possibilidade de manutenção da vida no planeta.

Nesses termos, diferentes discursos se apresentam no cenário nacional e internacional afirmando preocupação com os destinos da vida planetária diante da "questão ambiental" no interior dos quais tem se revelado hegemônico o que trata a "questão ambiental" como equivalente à "crise ambiental", identificando suas raízes no desperdício e/ou no limite dos recursos naturais, na produtividade e consumo em alta escala. Nessa medida, as "saídas" propostas têm em comum a preocupação de garantir a manutenção dos processos de valorização do capital articulada à necessária minimização dos danos à natureza. Articulam-se a essas interpretações as propostas de uso de "tecnologias limpas", "economia verde", "consumo consciente" como formas de enfrentamento aos chamados problemas ambientais no contexto de apelo ao "desenvolvimento sustentável".

Nessa perspectiva de desenvolvimento econômico combinado à preservação ambiental vem se destacando, em nível nacional, a proposta apresentada pelo Ministério da Pesca e Aquicultura (MPA) sob o signo de reforma aquária. Com a justificativa de promover a "democratização do acesso a água para criação de pescados” no território nacional e de inserir o país no conjunto dos maiores produtores de pescado do mundo, o Estado apresenta mais um dos seus "grandes projetos de desenvolvimento" em curso no Brasil. No entanto, uma observação crítica dessa proposta aponta que a mesma se articula com a privatização, enquanto ideário clássico do neoliberalismo e, nesse sentido, sua intencionalidade é marcada muito mais pelos compromissos com o subsídio direto à aquicultura - enquanto nova modalidade do ramo da pesca industrial — do que com a suposta "sustentabilidade" do setor pesqueiro. Depreende-se dessa última assertiva que nossa abordagem parte de uma perspectiva analítica que se contrapõe ao discurso hegemônico, ao entender que a "questão ambiental" 
se vincula intimamente à ordem burguesa, estando a essa última interditada a possibilidade de promover qualquer iniciativa séria de sustentabilidade ambiental. Dito de outro modo, a "questão ambiental" e o modo capitalista de produção conformam uma unidade, não havendo, portanto, compatibilidade entre capitalismo e preservação ambiental.

Tendo isso por suposto, este artigo se propõe a problematizar a reforma aquária mediante duas afirmações centrais: 1) a reforma aquária se expressa como uma das ações da contrarreforma do Estado brasileiro em tempos de crise do capital e, ao fazê-lo, 2) se articula diretamente à política econômica recomendada por organismos internacionais que busca reconfigurar a divisão internacional do trabalho, por meio da reprimarização das economias periféricas - movimento no interior do qual a apropriação privada dos recursos naturais é central.

\section{Contextualizando elementos fundantes: crise do capital, "questão ambiental" e a contrarreforma do Estado}

Para abordar a reforma aquária proposta no Brasil sem desconectá-la de suas determinações é fundamental situá-la no interior do debate sobre a atual crise do capital e alguns de seus desdobramentos que se apresentam essenciais a uma contextualização do tema.

Desde sua gênese o sistema capitalista é marcado pela ocorrência alternada de momentos de crises e de fases de expansão, cujas alterações ocorrem em relação ao período histórico e ao grau de desenvolvimento das forças produtivas. Essas crises expressam o caráter contraditório desse sistema e lhes são inerentes, além de funcionais, na medida em que criam as condições para a emergência de uma nova fase de expansão (Braz e Netto, 2011). Nesse sentido, crise não representa possibilidade de extinção do capitalismo. Afinal, "crises de intensidade e duração variadas são o modo natural de existência do capital: são maneiras de progredir para além de suas barreiras imediatas e, desse modo, estender com dinamismo cruel sua esfera de operação e dominação" (Mészáros, 2011, p. 795). 
Especialmente a crise que vem se aprofundando desde os anos 1970 guarda particularidades, não sendo equivalente à chamada crise cíclica. Entendemos que não cabe aqui, por razões de espaço, uma abordagem mais detalhada do tema que é, aliás, objeto de ampla e conhecida literatura, mas devemos, ao menos, situar seus aspectos fundamentais, considerando que esta crise é determinante de todas as variáveis presentes nas reflexões que se seguem.

Mészáros (2011) denomina a crise atual de "crise estrutural do capital" e evidencia seus principais aspectos que nos auxiliam a pensar sua "novidade histórica", quais sejam: o caráter universal (não se restringe a determinada esfera e/ou ramo particular de produção); o alcance global (atinge vários países, tem abrangência planetária); a escala de tempo permanente; seu modo de se desdobrar denominado rastejante (uma vez que não há momentos específicos de ápice).

Já nos termos de Mandel (1985), trata-se de uma "onda longa recessiva", cujos fundamentos se devem à crescente elevação da produtividade capitalista obtida com a mudança na base técnica da produção em meio aos chamados "30 anos gloriosos". Dessa vez a crise de superprodução foi provocada pelo advento da microeletrônica associada a outros componentes do capital constante que vão ampliar seu peso em relação ao capital variável na "composição orgânica do capital" (Marx, 2001). Sendo esse movimento inerente à busca dos superlucros, ao se generalizar para o conjunto dos grupos monopolistas, a partir do final dos anos 1960, vai gestar exatamente seu contrário: a queda tendencial na taxa de lucros - problema que atinge, em cheio, as possibilidades de valorização ampliada do capital até o presente momento.

Pensando-se na sociedade, de um modo mais amplo, muitos são os problemas oriundos dessa crise. O crescimento mundial dos índices de desemprego é, sem dúvida, um dos mais visíveis, por ser a expressão mais direta da redução do capital variável empregado na produção capitalista. O desemprego estrutural é, ao mesmo tempo, fator determinante da insuperabilidade da crise nos termos do próprio capital, já que esse fenômeno responde pela significativa redução do mercado consumidor e, portanto, pela queda nas taxas de lucro. Entretanto, esse problema é inerente às crises cíclicas e já esteve presente, com outras proporções, nas crises anteriores vivenciadas pelo capital 
nos séculos XIX e XX. Mas existe um elemento singular associado à crise atual: a sua dimensão ambiental.

É preciso dizer que a questão ambiental (ou, para alguns, crise ambiental) aparece, como tal, exatamente nos anos 1970 quando, "coincidentemente", tem início a atual onda longa recessiva. ${ }^{1}$ Essa coincidência é apenas aparente, pois qualquer observador mais atento do quadro gestado pelos "trinta anos gloriosos" verá que o aumento constante da produtividade sob as bases fordistas ampliou, em muito, a apropriação privada da natureza para fins de reprodução ampliada do capital. Ou seja, o capitalismo lidou historicamente com a natureza do mesmo modo predatório que tem lidado com a força de trabalho: o crescente grau de intensidade da apropriação privada da natureza como parte das matérias-primas que ingressam no processo produtivo não permite que decorra o tempo necessário à sua reprodução/reposição. Em decorrência disso entra em cena a escassez e, em alguns casos, a iminente finitude dos recursos naturais, enquanto fatores que condicionam, profundamente, as atuais alternativas debatidas para superação da crise.

Essas têm se plasmado, por parte do capital, em várias e simultâneas direções, podendo, para fins didáticos, ser reunidas em dois grandes grupos: as mudanças no chamado "regime de acumulação" e as que dizem respeito ao "modo de regulação" (Aranha, 1999), estando respectivamente referidas ao mundo da produção e ao Estado.

As alterações no regime de acumulação delineiam a chamada acumulação flexível (ou reestruturação produtiva). Como se sabe, em função das inúmeras pesquisas já disponíveis sobre o assunto, esta implica o oposto da "produção em massa" fordista, possibilitando ajustes na produção que minimizam os problemas postos na realização da mais-valia e se associa a padrões de exploração da força de trabalho que reeditam modalidades do capitalismo concorrencial ${ }^{2}$ revestidas de aparente modernidade.

1. É praticamente unânime, entre os estudiosos do tema, o marco da Conferência de 1972 para indicar a importância assumida por essa questão no interior das sociedades capitalistas, especialmente dos países cêntricos.

2. Referimo-nos, por exemplo, à associação entre trabalho escravo, pagamento por peça, amplas jornadas de trabalho e outros mecanismos que em seu conjunto, compõem a precarização do trabalho contemporâneo. 
Ainda situando a reestruturação produtiva, não podemos deixar de mencionar o peso da variável ambiental em seu interior. Isso significa dizer que, associado às iniciativas de produção flexível, o capital adota uma série de medidas no trato com a natureza que pretendem refletir o ideário da sustentabilidade.

No que diz respeito à escassez de recursos naturais, o capital investe na pesquisa de novas matérias-primas, na recomposição da base de fornecimento em caso de recursos renováveis (reflorestamento, por exemplo) além de alterações nas regras mercantis. A ciência econômica incorpora os custos ambientais a seus cálculos, atribuindo valor aos elementos antes gratuitos (o ar, os oceanos, a água) ${ }^{3}$ à medida que desenvolve o conceito de internalização das (antes consideradas) externalidades. [...] Diante dessa realidade, os economistas ecológicos propõem políticas econômicas que tenham como finalidades: 1) orientar a utilização mais eficiente dos recursos ambientais; 2) a substituição de recursos não renováveis por recursos renováveis; e, por fim, 3) a redução de processos contaminantes que estão alterando os ciclos biogeoquímicos de muitos ecossistemas [...]. (Silva, 2010, p. 118, 120)

Em decorrência dessas medidas de reestruturação produtiva, o Estado também passa por transformações em seu papel de regulador da economia, assumindo novas e liberais tarefas para impulsionar a retomada da acumulação capitalista. No contraponto ao formato de regulação do período fordista, o Estado "recicla-se", sob o neoliberalismo, iniciando um amplo processo de desregulamentação para viabilizar muitas das necessidades postas pela reestruturação produtiva.

A desregulamentação responde, concretamente, pela tendência de recuo ou redução das legislações dos Estados nacionais em relação a vários aspectos importantes para a mobilidade do capital "globalizado". Responde, portanto, pela falácia ideológica do "fim dos Estados nacionais" e do mito da "aldeia global", já que nem sempre esse movimento é globalmente seguido e restringe-se, em seus aspectos mais deletérios, aos países de capitalismo periférico. Os exemplos mais ilustrativos dessa tendência são vistos na regulação do trabalho,

3. Mais adiante veremos como esses elementos comparecem na proposta de reforma aquária. 
amplamente flexibilizada para possibilitar a precarização das relações trabalhistas nos níveis que se observa atualmente ${ }^{4}$ e tornar a exploração da força de trabalho nestes países ainda mais barata do que sempre foi (Santos, 2012). No contraponto a isso, observe-se como o protecionismo econômico permanece forte nos países de capitalismo central — tanto no que se refere à circulação de mercadorias, como à circulação de trabalhadores, estimulando fortemente a xenofobia.

Esse processo assumiu contornos dramáticos, no caso brasileiro, em decorrência do que Behring (2008) caracterizou como contrarreforma do Estado, implementada, de modo mais sistemático e explícito, a partir dos governos FHC e ainda em curso (com novas nuances) até os dias atuais. Estamos inteiramente de acordo com a razão, bastante conhecida, pela qual a autora renomeia como contrarreforma este processo, originalmente chamado pelos governos de refor$m a$ do Estado. O teor destas medidas não tem absolutamente nada a ver com as reformas em seu sentido clássico, qual seja, o das propostas defendidas pelo movimento operário socialista no início do século XX, cujo sentido, marcado pela busca da equidade, é totalmente descaracterizado neste caso, indicando um "profundo retrocesso social em beneficio de poucos" (Behring, 2008, p. 22; grifos originais).

O polo irradiador dessas ideias são os organismos internacionais. Logo, o receituário, adquire particularidades no interior dos diferentes países periféricos, mas não guarda nenhuma originalidade em sua essência. Antes de prosseguirmos, cabe aqui uma nova advertência: assim como no caso da crise capitalista, nossa abordagem sobre a contrarreforma do Estado no Brasil será também panorâmica, sinalizando, em seu interior, alguns pontos bastante precisos.

Entre as muitas medidas identificáveis nesse grande "pacote" nos interessa, mais de perto, destacar como a desregulamentação — rapidamente definida

4. As mudanças adotadas no Brasil no contexto internacional de reestruturação do capital e apresentadas sob o caráter de reforma do Estado se configuram em desmonte sistemático da estrutura estatal, fortalecimento do mercado, aprofundamento da precarização do trabalho, regressão de direitos historicamente conquistados e assinalados na Constituição Federal de 1998, principalmente os direitos sociais. No Brasil, com o fortalecimento do projeto neoliberal nos anos 1990, o Estado passou por um intenso processo de redução de suas respostas às demandas do trabalho mediante minimização de sua atuação na operacionalização das políticas sociais, mas mantendo uma forte e funcional atuação em prol dos interesses do capital. 
acima enquanto traço essencial do novo modo de regulação, requerido pelo capital em crise - se associa à privatização, delineando uma política econômica para países periféricos que têm uma clara intencionalidade: reorganizar a divisão internacional do trabalho, reservando a esses países um lugar determinado pelo que tem sido chamado de "reprimarização" (Gonçalves, 2012) das suas economias.

Tendo por suposta a compreensão do quadro histórico de extrema heteronomia (Fernandes, 2006) das decisões sobre o desenvolvimento de nosso país, o que se passa no momento atual pode ser visto como sua atualização, em patamares ainda mais regressivos, se comparado ao que se passou no período da igualmente subordinada política de "modernização conservadora", implementada sob os auspícios dos governos militares. É o que Tavares (1999, apud Behring, 2008) chamará de "caráter destrutivo não criador e conservador" da contrarreforma, em oposição à modernização conservadora ocorrida no pós-1964.

Naquela quadra histórica, o fluxo dos Investimentos Externos Diretos (IEDs) atraídos para o Brasil levou a uma diversificação do potencial produtivo, incorporando, ainda que de modo associado e dependente, componentes tecnológicos da produção industrial. No entanto, o início da crise capitalista e o visível refluxo dos IEDs na produção levaram à "crise desse padrão de desenvolvimento" (Santos, 2012) e, já a partir dos anos 1980, à destruição de parcela importante do recém-montado parque industrial brasileiro. Isso conduziu, progressivamente, os

Estados nacionais [a] dificuldades em desenvolver políticas industriais, restringindo-se a tornar os territórios nacionais mais atrativos às inversões estrangeiras. [...] uma das funções econômicas do Estado - a qual Mandel caracteriza como sendo de assegurar as condições gerais de produção - passou a ser garantia dessa atratividade, a partir de novas relações entre este e grupos mundiais, onde o primeiro tem lugar cada vez mais subordinado. Dentro disso, os Estados nacionais restringem-se a: cobrir o custo de algumas infraestruturas (sobre as quais não há interesse de investimento privado), aplicar incentivos fiscais, garantir escoamentos suficientes e institucionalizar processos de liberalização e desregulamentação em nome da competitividade. (Behring, 2008, p. 59) 
Nesse contexto, o Brasil é levado a reorientar "a parte mais competitiva da economia para a exportação (o que implica [...] um largo processo de desindustralização ${ }^{5}$ e volta a certas "vocações naturais')" (Behring, 2008, p. 61). Estes são os termos que definem a reprimarização: o retorno à economia essencialmente baseada na produção de produtos primários, agroexportáveis ou, no máximo, de baixa tecnologia agregada. Numa análise da estrutura das exportações de produtos industriais, segundo a intensidade tecnológica, Gonçalves (2012, p. 9) expõe que

A participação (média móvel 04 anos) dos produtos altamente intensivos em tecnologia reduz-se $13,1 \%$ em 2002 para $8,8 \%$ em 2006 e 8,1\% em 2010, enquanto a participação de produtos das indústrias de médio-baixa tecnologia aumenta de $21,7 \%$ em 2002 para $24,2 \%$ em 2006 e $25,1 \%$ em 2010.

Entretanto, é importante deixar claro que o retorno às "vocações naturais" não se confunde com qualquer perspectiva nacionalista. O perfil dos IEDs no Brasil atualmente está longe de se caracterizar apenas sob a forma de capital especulativo, como tem sido mais recorrentemente sinalizado pelos autores de orientação crítica. São evidentes, nos últimos censos do IED no Brasil, ${ }^{6}$ as tendências ao seu crescimento também nos setores produtivos primários voltados à exportação, com as correspondentes vantagens concedidas ao setor produtivo de um modo geral em termos de incentivos fiscais, favores e concessões tributárias - exemplos de desregulamentação do Estado em busca de se tornar "atrativo". Esse censo mostra que no período 2000 a 2009 o estoque de IEDs concentrado no setor primário passou de 2,3\% para 15,4\% (Gonçalves, 2012).

5. "A desindustrialização pode ser definida como a tendência de queda da relação entre o valor adicionado na indústria de transformação e o PIB. Nos países em desenvolvimento, a desindustrialização é prematura e resulta do viés de deslocamento da fronteira de produção na direção dos produtos intensivos em recursos naturais. Este deslocamento ocorre, principalmente, na fase ascendente dos preços das commodities no mercado mundial" (Gonçalves, 2012, p. 7).

6. O censo dos investimentos estrangeiros no país é realizado pelo Instituto de Estudos para o Desenvolvimento Industrial (IEDI), que classifica os tipos de estratégias exercidas pelas filiais de empresas estrangeiras no Brasil, segundo as atividades econômicas e a propensão das empresas a exportar e importar (Campos e Fernandes, 2008). 
Somente compreendendo esse movimento da economia brasileira em meio à crise capitalista recente é que se torna possível situar os interesses em jogo quando FHC retoma, em níveis mais agressivos do que os possíveis aos governos democráticos que lhe antecederam, as medidas de privatização de setores produtivos estatais extremamente importantes. Referimo-nos, mais especificamente, à privatização do setor petrolífero e de mineração, não por acaso situados estrategicamente como parte da extração de riquezas naturais — razão pela qual a dimensão ambiental da crise não pode ser menosprezada em sua compreensão. Não é preciso nos estender para explicar o quanto ampliar o domínio privado sob a natureza é decisivo para a lucratividade do capital nos dias atuais e, estando esse domínio associado a uma política econômica que barateia os custos de produção com a desregulamentação, sem dúvida não há perspectiva mais favorável para tais investidores.

Esse panorama é fundamental para ressaltar como a reforma aquária conjuga todos os elementos abordados até aqui: 1) está inserida nas iniciativas de desregulamentação e privatização postas pela contrarreforma do Estado como resposta à crise do capital; 2) reflete a perspectiva de "internalização de externalidades" ambientais aos custos de produção; 3 ) indica uma expressão particular do movimento de reprimarização da economia brasileira, por meio do favorecimento da psicultura/aquicultura voltada para a exportação, como veremos a seguir.

\section{0 "canto da sereia": 0 significado socioeconômico e ambiental da reforma aquária no Brasil}

O Brasil conta com 12\% da água doce do mundo e um litoral com mais de 8 mil quilômetros de extensão. Em um hectare de lâmina d'água, na aquicultura, podemos produzir cem toneladas de pescado. Temos todas as oportunidades para nos tornarmos os maiores produtores de peixe do mundo. (MPA, 2013) ${ }^{7}$

7. Disponível em: <http://www.mpa.gov.br/index.php/topicos/1499-ministro-defende>. Acesso em: 2 jun. 2014. 
O discurso supracitado do então ministro da Pesca e Aquicultura, Marcelo Crivella, ao defender a reforma aquária no Brasil, tende a seduzir os expectadores menos atentos, quando na verdade trata-se de autorizar o uso de águas de domínio da União para aquicultura. Isso significa dizer que o Ministério da Pesca e Aquicultura (MPA) defende o fortalecimento da aquicultura mediante exploração de águas de domínio da União por pessoa física ou jurídica, por intermédio de licitações na modalidade "Concorrência", para autorização/ cessão de uso. Pretende-se alavancar a instauração de parques e áreas aquícolas nessas águas para ampliar a produção de pescado no país e a conquista de mercados internacionais.

Esse risco de sedução se aprofunda e pode se estender aos otimistas ingênuos quando o referido ex-ministro, ao receber em seu gabinete algumas lideranças do Movimento Nacional dos Pescadores e Pescadoras Artesanais, destacou a pesca artesanal como uma prioridade do governo federal, além do reconhecimento de sua relevância social e econômica no país. Para traduzir tal prioridade, explicou:

[O] governo federal pretende democratizar o acesso a água para a criação de pescados, promovendo a "reforma aquária" e evitando que os grandes reservatórios de hidrelétricas fiquem ociosos ou nas mãos das companhias geradoras de energia. [...]. Não estamos privatizando as águas. Estamos trabalhando para que os $0,5 \%$ desses espaços ajudem a gerar emprego e renda no nosso país, garantindo pescado de qualidade para a nossa população. Não podemos aceitar que com todo o nosso potencial e oferta de água, o país tenha que importar US\$ 1 bilhão em pescados por ano. (MPA, 2013)

O discurso propalado pelo então ministro Crivella sugere que a defesa da reforma aquária se sustenta na perspectiva de garantir a "democratização do acesso a água no Brasil" e, com isto, a geração de emprego, renda e crescimento econômico. No intuito de ir um pouco além do indicado pela aparência fenomênica e tangenciar o sentido fundamental da proposta em exame, convém

8. Disponível em: <http://www.mpa.gov.br/index.php/topicos/2224-ministro-crivella $>$. Acesso em: 2 jun. 2014. 
oferecer mais elementos para a análise. Nessa direção, seguem alguns trechos de um texto de Crivella, veiculado pelo jornal Folha de S.Paulo:

A consciência crítica e o inconformismo com o atraso e a miséria, marcas do governo da presidenta Dilma, garantem ao povo brasileiro o direito de ser otimista. O que queremos ser e seremos é um país cuja indústria pesqueira alcance o mesmo desenvolvimento que a avícola ou a bovina.

O processo começou: o Plano Safra da Pesca e Aquicultura9 e a desoneração tributária, ao se incluir o pescado na cesta básica, foram os primeiros passos. Agora, a presidenta determinou que o Ministério da Pesca e Aquicultura e o Ministério do Meio Ambiente apresentem proposta para simplificação de licenciamento ambiental para a aquicultura nas águas da União.

A ideia é o desenvolvimento da aquicultura de zero impacto ambiental. Consiste, basicamente, na dispensa do licenciamento ambiental nos parques e áreas aquicolas em águas da União, em até meio por cento do reservatório, barragem, açude etc., a ser instalada de maneira gradual e com monitoramento ambiental. Ao primeiro sinal de comprometimento dos parâmetros do uso múltiplo da água, interrompe-se a instalação. (Crivella, 2013; grifos nossos)

É importante reter aqui alguns elementos desse discurso, conectando-os às análises precedentes. Na medida em que crescem as tendências de reprimarização, enquanto estratégia de sustentação da economia do país, crescem os investimentos de capital estrangeiro em setores voltados para a exportação e, segundo Campos e Fernandes (2008, p. 492) é, “de esperar que nesse grupo predominem as empresas voltadas para a exploração de setores primários ou industriais que utilizem intensivamente recursos naturais e que apresentem valores elevados para a exportação e pequenos para a importação".

Este parece ser, precisamente, o caso da aquicultura, que, segundo pretensões do ex-ministro, pode alcançar com a privatização das águas e a desregu-

9. O Plano Safra da Pesca e Aquicultura é um programa do governo federal que tem o objetivo de "estimular o desenvolvimento do setor por meio de linhas de crédito para o aumento da produção e a geração de emprego e renda. [...] O crédito será concedido pelo Banco Nacional do Desenvolvimento Econômico e Social (BNDES), Banco do Nordeste, Banco do Brasil, Banco da Amazônia, Caixa Econômica Federal e Cooperativas de crédito.” Disponível em: <http://www.mpa.gov.br/safra/>. Acesso em: 2 jun. 2014. 
lamentação de seu uso - concretamente traduzida pela simplificação do licenciamento ambienta ${ }^{10}$ — "o mesmo desenvolvimento das [atividades] avícola ou a bovina". A comparação não poderia ser mais ilustrativa para demarcar o padrão de produção a ser estimulado: a pesca industrial. Trata-se da pesca que é "praticada por pessoa física ou jurídica e [envolve] pescadores profissionais, empregados ou em regime de parceria por cotas-partes, utilizando embarcações de pequeno, médio ou grande porte, com finalidade comercial" (Brasil, 2009).

Nesse momento cabe uma pequena incursão para destacar elementos do que tem sido historicamente a intervenção pública no setor pesqueiro e sua diversidade. O Estado brasileiro investiu, prioritariamente, no segmento industrial da pesca, o que significa dizer que este não é o único segmento existente em seu interior. A atividade pesqueira no Brasil é bastante antiga e praticada, originalmente, por trabalhadores residentes em regiões costeiras e/ou ribeirinhas, com uma cultura e modo de vida considerado "tradicional". Estes trabalhadores, chamados de pescadores artesanais, buscam, por meio dessa atividade, a subsistência familiar e alguma renda. A pesca artesanal é definida atualmente, de acordo com o artigo $8^{\circ}$ da Lei n. 11.959/2009 como sendo "praticada diretamente por pescador profissional, de forma autônoma ou em regime de economia familiar, com meios de produção próprios ou mediante contrato de parceria, desembarcado, podendo utilizar embarcações de pequeno porte" (Brasil, 2009).

Conforme já mencionamos, a modernização conservadora do pós-1964 atuou fortemente no sentido de "modernizar" a produção industrial, mas isso não ocorreu somente nas indústrias stricto sensu. Essa diretriz também impactou atividades de natureza rural, como a agricultura (por meio dos processos de mecanização e quimificação, estímulos à monocultura de natureza agroindustrial etc.) e a pesca. No mesmo movimento de criação da Sudene (Superintendência do Desenvolvimento do Nordeste) e da Sudam (Superintendência do Desenvol-

10. "O licenciamento ambiental é o procedimento administrativo pelo qual o órgão ambiental autoriza a localização, instalação, ampliação e operação de empreendimentos e atividades utilizadoras de recursos ambientais, consideradas efetiva ou potencialmente poluidoras ou daquelas que, sob qualquer forma, possam causar degradação ambiental". Disponível em: <http://www.mma.gov.br/governanca-ambiental/portal-nacional-de-licenciamento-ambiental/licenciamento-ambiental>. Acesso em: 2 jul. 2014. 
vimento da Amazônia), foi criada a Sudepe (Superintendência do Desenvolvimento da Pesca). Sua funcionalidade foi clara: subsidiar, pela via de políticas de crédito (mas não só), a "modernização" do setor pesqueiro, o que implicava o estímulo à pesca industrial em detrimento da pesca artesanal.

A intensa exploração dos recursos pesqueiros favorecida pelo crescimento da pesca industrial estimulada pela legislação vigente no período provocou, entretanto, a diminuição da produção, a partir da década de 1980, fazendo com que o setor entrasse em crise. Cardoso aponta duas razões explicativas deste fato:

A primeira diz respeito à total ausência de planejamento que acompanhou os investimentos da SUDEPE e que no oportunismo da maré dos incentivos fiscais levou à criação de estruturas de terra para beneficiamento do setor pesqueiro, muitas vezes inoperantes, ociosas e de vida curta marcada por escândalos financeiros e administrativos. A segunda remete às análises estruturais da atividade pesqueira [e ao consequente exaurimento do estoque em função da sobrepesca]. $\mathrm{O}$ fato da pesca basear-se na captura de recursos não totalmente controlados, não permite que a racionalidade capitalista se imponha, em especial no setor da produção. (Cardoso, 2009, p. 6-7)

Isso para ficar nos aspectos macroeconômicos dessa crise, porque ainda poderiam ser expostos aqui outros ângulos relacionados às consequências socioambientais deste modelo de exploração da pesca, como o crescente desemprego e assalariamento dos pescadores artesanais, submetidos a relações de trabalho bastante precárias nas indústrias pesqueiras. O fato é que o exaurimento, inclusive estrutural, das possibilidades de continuidade da indústria pesqueira naqueles moldes fez refluir a importância econômica da atividade no conjunto da balança comercial brasileira. Esse mesmo fator aprofundou a crise de "sustentabilidade" da pesca artesanal, que hoje enfrenta sérias dificuldades para se manter como tal após esse aumento predatório do esforço de pesca, originado pela política da modernização conservadora.

A sobrepesca de algumas espécies, a pesca predatória de outras tantas e a destruição de ecossistemas de alta produtividade são algumas das consequências que acompanharam o desenrolar do projeto de modernização do setor pesqueiro, 
contribuindo para a redução do pescado situado junto à costa. Ainda junto à costa, nas áreas de atuação da pesca artesanal, verificou-se um aumento da disputa pelo pescado. Parte da frota industrial atuando com técnicas predatórias para baixas as profundidades próximas à costa acarretaram a diminuição da oferta de pescados para pescadores artesanais, cujos meios de produção não lhes possibilitam um deslocamento mais amplo, acirrando disputas pela apropriação destes espaços e do pescado neles contido. (Cardoso, 2001, p. 28)

Considerar esse passado recente e suas consequências contemporâneas é parte significativa do que chamamos atenção como imperativo para penetrar a aparente inquestionabilidade da reforma aquária. É parte significativa, portanto, de nossa argumentação crítica a essa ideia, pois parece evidente se tratar de uma nova tentativa para beneficiar o capital empregado no setor pesqueiro, agora com métodos de produção que independem do tempo de reprodução natural das espécies, ou seja, a criação das "fazendas de peixe", ${ }^{11}$ por meio da aquicultura.

Esse setor tem sido positivamente avaliado como um dos que mais crescem em se tratando do comércio mundial, o que torna a sua expansão quase um imperativo - ideia, aliás, compatível com o "espírito" da ortodoxia do pensamento único que "reina" no campo das diretrizes macroeconômicas desde FHC. A própria FAO (Organização das Nações Unidas para Alimentação e Agricultura) reconhece o decréscimo do potencial da pesca extrativa diante da intensiva exploração a que foi submetido o estoque pesqueiro natural, apostando "seriamente nas potencialidades do Brasil em ser um grande exportador nos próximos anos e décadas, por ser um país privilegiado em possuir as condições indispensáveis para a expansão da atividade" (Malafaia Júnior, 2010, p. 15). No período 2003-07, o crescimento médio da produção da pesca e aquicultura no Brasil foi de $2 \%$ anuais. A partir de 2007, registram-se crescimentos na casa dos 7\%, e as projeções do MPA para 2011 eram de 15,3\%. A expectativa projetada chegou perto de se realizar, pois os dados de 2011 indicam que a produção cresceu $13,2 \%$ a mais do que em $2010 .{ }^{12}$

11. Essa é a denominação usualmente adotada para designar os criatórios de peixes na aquicultura.

12. Disponível em: <http://www.mpa.gov.br/index.php/imprensa/noticias/2140-mpa-lanca-boletimestatistico-da-pesca-e-aquicultura-2011>. Acesso em: 3 ago. 2014. 
Analisando-se esse quadro, não pode haver dúvida sobre duas questões. Primeiramente, sobre o fato de esse crescimento estar associado à existência de um ministério específico (criado em 2003) e, portanto, ao forte papel do Estado no incremento à aquicultura entre as prioridades governamentais. Para tanto, basta observar os incentivos e políticas previstos nos Planos Safra Pesca e Aquicultura, em que vemos que o peso dessa última é incomparavelmente maior do que o da pesca artesanal.

A permanência desta tendência como parte das diretrizes do atual governo do PT também foi enfatizada entre as prioridades do ministro da Pesca e Aquicultura Eduardo Lopes, empossado pela presidente Dilma Rousseff em março de 2014:

Eu quero ver efetivamente o que foi realizado até agora no Plano Safra e trabalhar para que a gente consiga atingir um bom resultado. A produção no ano passado cresceu quase que $70 \%$ comparada ao ano anterior. A meta é manter a mesma média, o que colocaria o Brasil produzindo 4 milhões de toneladas. (MPA, 2014) ${ }^{13}$

Em segundo lugar, é inegável a funcionalidade da privatização das águas da União para o crescimento da aquicultura: elas fazem parte do cálculo que envolve as "condições favoráveis" dessa atividade no Brasil e só se tornarão efetivamente favoráveis se os custos para a exploração desse recurso forem os mais baixos possível, conforme opera a lógica do capital em qualquer campo de sua produção. Por essa razão, a reforma aquária envolve iniciativas de desregulamentação do licenciamento ambiental no referido setor. Podem ser citados, a título de exemplo dessas ações, editais de licitação lançados a partir de 2009, na modalidade "Concorrência" (dos tipos "maior lance ou oferta" para cessão onerosa; "seleção não onerosa por tempo determinado") com vistas à obtenção, por pessoa física ou jurídica de direito privado, de autorização/cessão de uso de espaços físicos em corpo d'água de domínio da União na modalidade de área aquícola. ${ }^{14}$

13. Disponível em: <http://www.mpa.gov.br/index.php/imprensa/noticias/2599-dilma-empossa-eduardo-lopes-como-novo-ministro-da-pesca-e-aquicultura $>$. Acesso em: 25 jul. 2014.

14. Esses editais de licitação estão disponíveis para consulta no endereço virtual: Disponível em: $<$ http:// www.mpa.gov.br/index.php/aquiculturampa/licitacoes-de-areas-aquicolas/2009>. Acesso em: 22 jun. 2014. 
Nessa articulação entre a contrarreforma do Estado e o ideário da sustentabilidade, Silva (2010, p. 119) esclarece que, como parte da lógica de internalizar as externalidades, a economia ambiental propõe efetivamente a privatização dos "recursos" naturais escassos e não mercantis (ar, água).

De acordo com [estes] pressupostos [...] a única forma de gerenciar adequadamente os recursos naturais seria privatizando-os, o que implica uma drástica, porém planejada, redução dos bens públicos. Trata-se, neste caso, de [...] estabelecer ou fixar preços para os bens públicos em conformidade com a lógica de mercado. [...] Neste sentido, fixar cotas de contaminação, por exemplo, é uma forma de privatizar um elemento natural público, o que tende a abonar a culpa do poluidor privado: uma vez pagando pelo que contamina, transfere para o espaço público - camada de ozônio, mares, atmosfera, entre outros — os problemas ambientais por ele gerados.

Avançando na problematização da proposta de reforma aquária no Brasil, outros argumentos para sua sustentação, além do propalado "desenvolvimento sustentável", são o apelo ao nacionalismo e à superação do "atraso", mediante expansão econômica que seria promovida pelas "novas tecnologias" associadas à cadeia produtiva da psicultura. Ainda conforme expresso no mesmo texto do ex-ministro:

Estamos determinados e confiantes de que, com trabalho e pesquisa, iremos nos redimir das amarras que ancoram o nosso progresso e promover o desenvolvimento sustentável da indústria pesqueira.

Com o plano [Safra], a Embrapa Pesca e Aquicultura ganha nova força para desenvolver pacotes tecnológicos. O seu presidente lembra que, em um hectare de terra, o melhor pecuarista brasileiro consegue produzir uma tonelada de carne bovina por ano, enquanto, no mesmo tempo, em um hectare de água, pode-se produzir 200 toneladas de peixe. (Crivella, 2013; grifos nossos)

Este argumento só esquece de mencionar quem são os principais beneficiários desse "desenvolvimento", uma vez que a produção sob esse sistema envolve uma série de custos que aumentam o chamado "valor agregado" do pescado, pois sua cadeia produtiva é extremamente complexa. Logo, nem o 
pequeno produtor se beneficiará - pois está distante do acesso às condições de produção desse tipo de mercado — , tampouco o consumidor brasileiro, que deverá ter pescado cada vez mais caro nos mercados.

A chamada cadeia produtiva do pescado compreende, por exemplo, "desde os fornecedores de insumos e responsáveis pelo processamento dos peixes, até a utilização de canais de marketing que tornarão o produto disponível ao consumidor final" (Malafaia Júnior, 2010, p. 13). Isso implica falar, concretamente, das indústrias produtoras de ração (utilizada na alimentação dos peixes) e de equipamentos (tanques-rede, aeradores, bombas e aparelhos de monitoramento da qualidade da água), além dos investimentos em atividades laboratoriais. Em todos esses casos, que envolvem pesquisa e tecnologia, Malafaia Júnior (2010) indica que já são registrados investimentos de capital estrangeiro e, em alguns deles, como o dos equipamentos, o Brasil continuará dependendo de importações, pois "uma tendência relevante é que apesar de criações em viveiros escavados prometerem grande crescimento, o aumento da piscicultura em tanques-rede deverá ser superior e responsável por grande percentual na produção de peixes do futuro" (Idem, p. 13-14).

Fica claro, portanto, quem irá "ganhar" com o desenvolvimento intensivo da psicultura no Brasil a partir da reforma aquária: o grande capital aplicado na indústria pesqueira nacional, mas, principalmente, internacional que verá perspectivas de expansão dos seus negócios nos termos vantajosos já tratados aqui na seção precedente. Enquanto isso são reconhecidos os baixos índices de consumo de pescado no mercado interno. Dados oficiais de 2008 indicam $6,48 \mathrm{~kg} /$ per capita/ano no contraponto a $36,9 \mathrm{~kg}$ de carne bovina e $52,7 \mathrm{~kg} / \mathrm{per}$ capita de outras carnes (Malafaia Júnior, 2010). Sem dúvida os preços praticados no mercado pesqueiro jogam papel decisivo nesse comportamento alimentar, que, a nosso ver, só tende a se agudizar com o tipo de produção que se quer estimular e cujo destino não será a "mesa dos brasileiros", conforme quer fazer crer o ex-ministro:

Assim, o governo oferece alternativa produtiva melhor para os vultosos investimentos economicamente estéreis na especulação financeira. Nossos empresários são chamados a investir na produção de pescado para fazer do Brasil um dos maiores produtores do mundo. São chamados para suas empresas crescerem 
com um trabalho rentável e fascinante, mas também sublime, por ajudar no combate à fome.

Mas o mais importante é que centenas de milhares de famílias de pescadores e ribeirinhos poderão obter um lote aquícola e acrescentar ao patrimônio da nossa geração uma riqueza em proteína animal cujo potencial o BNDES comparou a um novo pré-sal. (Crivella, 2013; grifos nossos)

Não é surpresa que o trabalho do ex-ministro de Pesca e Aquicultura tenha recebido o reconhecimento de empresários brasileiros, a exemplo da premiação que lhe fora concedida pela Bolsa de Gêneros Alimentícios do estado do Rio de Janeiro como "personalidade estadual de 2013" — um troféu que homenageia empresas e líderes que contribuíram com o setor alimentício naquele estado.

Assim, cabe indagar de qual "democratização do acesso a água" está se tratando? Em que medida tornar o Brasil um dos maiores produtores de pescado do mundo trará melhores condições de vida à população brasileira e, especialmente aos pescadores e pescadoras artesanais, além do "direito de ser otimista" destacado pelo ex-ministro? Embora se apresente como democratização das águas, da propriedade capitalista (vide o chamamento a pequenos aquicultores a obterem um "lote aquícola"), e como uma "reforma" para beneficiar a todos os brasileiros com os pretensos ganhos econômicos articulados à preservação ambiental e ao combate à fome, já temos elementos para indicar as razões de esse discurso ser chamado aqui de "canto da sereia".

A reforma aquária se mostra essencialmente como um modo de desregulamentar a exploração dos recursos naturais, facilitando a expansão/diversificação de investimentos do capital. Portanto, traduz-se em mais uma estratégia para obter "mais do mesmo": expansão de nichos de mercado em tempos de crise do capital. Com essa proposta, o Estado brasileiro fortalece a lógica que reverte um bem comum (a água) ao caráter de mercadoria - um movimento que favorece a expansão do hidronegócio que significa, "“literalmente, o negócio da água'. É assim que o verbete do Dicionário da Educação do Campo (Fiocruz e Movimentos Sociais) define toda atividade econômica que tem a água como sua principal mercadoria" (Malvezzi, 2012). O hidronegócio, entretanto, está longe de se restringir à psicultura. $\mathrm{O}$ mesmo autor chama a atenção para o fato de que a "agricultura industrial consome $70 \%$ da água 
doce utilizada no mundo, portanto, é a principal atividade econômica interessada na água". ${ }^{15}$

Isso dá a exata dimensão do sentido da reforma aquária e do peso dos interesses econômicos que concorrem para sua viabilização. Sua configuração pode tornar realidade a privatização da água - um recurso natural que, além de essencial à preservação da vida, integra todos os processos de produção. Nestes termos, desvendar o "canto da sereia" implica evidenciar a importância econômica da água como "recurso", mas, sobretudo, o seu pertencimento à dimensão ambiental dos direitos humanos, o que torna também evidente que a reforma aquária prioriza interesses de mercado em detrimento de direitos fundamentais da população brasileira.

\section{Considerações finais}

O debate em torno da reforma aquária, embora relativamente desconhecido no interior do Serviço Social, tem uma importância significativa para o conjunto da sociedade brasileira. Nele estão imbricados diversos desdobramentos que, caso não sejam elucidados criticamente, podem esconder os impactos sociais, econômicos, políticos e ambientais que este processo terá em curtíssimo prazo. As reflexões aqui esboçadas objetivaram evidenciar os fundamentos dessa proposta e alguns de seus impactos sublinhando um campo fértil para outros estudos e pesquisas que aprofundem investigações a respeito. Consideramos essencial a ampliação do acervo crítico de conhecimentos disponíveis sobre a reforma aquária, principalmente em face da necessária resistência que deve ser socialmente protagonizada em sentido contrário. É fundamental, portanto, para finalizar este artigo, apontar duas questões que informam parcialmente contornos atuais do seu andamento.

A primeira delas é um panorama, ainda que embrionário, sobre o estágio de sua implementação. Em pesquisas para elaboração do presente artigo, não vislumbramos ainda uma alteração significativa no aparato legal do licencia-

15. Idem. 
mento para aquicultura. Está em vigência a resolução do Conselho Nacional de Meio Ambiente (Conama) n. 413, de 2009, recentemente alterada pela Resolução n. 459 de 2013. Esta última inclui a classificação de empreendimentos aquícolas quanto ao porte (pequeno, médio, grande) e potencial de severidade das espécies, cabendo ao órgão licenciador, mediante uso de critérios definidos, decidir pelo licenciamento simplificado ou não de empreendimentos considerados de pequeno e médio porte.

Sobre o licenciamento simplificado, a secretária de Planejamento e Ordenamento da Aquicultura Maria Fernanda Nince afirmou que a "resolução deixa mais ágil o processo de licenciamento pelo fato de trabalhar com uma licença única. Antes eram necessárias as licenças prévias, de instalação e de operação". ${ }^{16}$ Outra alteração se refere à possibilidade de emissão de "licença ambiental única", por meio de "procedimento simplificado", para os parques aquícolas situados em reservatórios artificiais. Dado o caráter recente dessas alterações, ainda não se pode apontar seu real significado no interior dos possíveis encaminhamentos para efetivação da reforma aquária proposta. Entretanto, já consideramos digno de nota a redução do tempo e dos procedimentos para obtenção da chamada licença simplificada, que precisa ser melhor observada em sua implementação para fornecer indícios empíricos das medidas desregulamentadoras.

A esse quadro acresce-se, no entanto, algo bastante concreto: a ocorrência sistemática de editais de licitação na modalidade "Concorrência", nos termos mencionados aqui (cf. item 2). São inúmeros os editais existentes no site do MPA a partir de 2009 que possibilitam o estabelecimento de concessões simplificadas de águas da União. Tal processo parece ter sido legalmente antecipado por meio do Decreto n. 4.895/2003, que, ao tratar da autorização do uso de águas de domínio da União para fins de aquicultura, em seu artigo 14 prevê a realização de processo seletivo público como parte dos requisitos à obtenção da autorização de direito de uso. ${ }^{17}$ Portanto, nos parece que a reforma aquária

16. Conama aprova licenciamento ambiental para aquicultura. Disponível em: $<\mathrm{http} / / /$ memoria.ebc. com.br/agenciabrasil/noticia/2013-09-14/conama-aprova-licenciamento-ambiental-para-aquicultura $>$. Acesso em: 2 jul. 2014.

17. Disponível em: <http://www.planalto.gov.br/ccivil_03/decreto/2003/D4895.htm>. Acesso em: 2 jul. 2014. 
tem se viabilizado por meio de ações que "diluem" a percepção social de sua operacionalização, enquanto não se flexibilizam, explicitamente, os critérios oficiais de licenciamento.

A outra questão a ser levantada como parte dos contornos atuais sobre o tema tem a ver com as formas de resistência a mais essa iniciativa de contrarreforma do Estado no Brasil. É o caso das denúncias protagonizadas pelo Movimento de Pescadores e Pescadoras Artesanais (MPP). Em debate realizado em 2012 pela Fundação Joaquim Nabuco, a pescadora Cícera Estevão Barbosa, representante do MPP, destacou como a carcinicultura (uma das modalidades da aquicultura, dedicada à criação de camarões em viveiros) "vem destruindo os manguezais e poluindo a água e a terra [...], pois utiliza veneno", ${ }^{18}$ ou seja, antibióticos e pesticidas que, ao serem despejados no ambiente após a lavagem dos tanques, são extremamente prejudiciais a qualquer tipo de vida naqueles ecossistemas.

$\mathrm{O}$ "direito ao meio ambiente ecologicamente equilibrado, bem de uso comum do povo e essencial à sadia qualidade de vida", constitucionalmente vigente segundo o artigo 225, estabelece, para sua efetividade, que se imponha "ao poder público e à coletividade o dever de defendê-lo e preservá-lo para as presentes e futuras gerações" (Brasil, 1988). Consideramos que a reforma aquária coloca o Estado na contramão desse papel de preservação do meio ambiente, pois a privatização das águas da União para fins de estímulo à aquicultura, além de toda a funcionalidade econômica para o grande capital, anteriormente assinalada, também possui impactos socioambientais que já estão sendo sentidos pelas "presentes gerações".

Nessa direção, o MPP vem fazendo o que estabelece o artigo 225, como parte da "coletividade" que também deve defender e preservar o meio ambiente. Nele temos parte importante da resistência, não só à reforma aquária, mas também ao conjunto de ações do governo brasileiro, que agravam conflitos socioambientais em territórios tradicionalmente ocupados por comunidades

18. Disponível em: $<$ http://www.fundaj.gov.br/index.php?option=com_content\&view=article\&id=128 3 :seminario-debate-territorio-pesqueiro-biodiversidade-cultura-e-soberania-alimentar\&catid=44:sala-deimpressa\&Itemid=183>. Acesso em: 2 jul. 2014. 
ribeirinhas, tais como a "Campanha Nacional pela Regularização do Território das Comunidades Tradicionais Pesqueiras". ${ }^{19}$

Entretanto, sabemos que o eco dessas vozes é extremamente frágil diante do poderio econômico do hidronegócio, razão pela qual destacamos a necessidade do conhecimento ampliado das consequências da reforma aquária. Se colocado a favor dessa e de outras formas de resistência, este conhecimento poderá expor as inverdades da sustentabilidade ambiental da aquicultura e, sobretudo, evidenciar a extensão dos níveis de mercantilização existentes nesta sociedade.

Recebido em: 7/7/2014 - Aprovado em: 10/3/2015

\section{Referências bibliográficas}

ARANHA, L. Educação e trabalho no contexto da terceira revolução industrial. São Cristóvão: Ed. da UFS, 1999.

BEHRING, E. R. Brasil em contra-reforma: desestruturação do estado e perda de direitos. São Paulo: Cortez, 2008.

BLACK, C. Um estudo sobre o investimento direto estrangeiro e a balança comercial no Brasil, nas últimas décadas. Indicadores Econômicos FEE, Porto Alegre, v. 41, n. 3, 2014. Disponível em: $<$ http://revistas.fee.tche.br/index.php/indicadores/article/viewFile/3047/3212>. Acesso em: 21 jun. 2014.

BRASIL. Constituição da República Federativa do Brasil, 5 out. 1988. Disponível em: $<$ http://www.senado.gov.br/legislacao/const/con1988/con1988_05.10.1988/art_225_. shtm>. Acesso em: 27 jun. 2014.

. Lei n. 11.959, de 29 de junho de 2009. Dispõe sobre a política nacional de desenvolvimento sustentável da aquicultura e da pesca, regula as atividades pesqueiras,

19. Sobre isso, vale consultar o blog do MPP. Disponível em: <http://campanhaterritorio.blogspot.com.br/>. Acesso em: 2 jul. 2014. 
revoga a Lei n. 7.679, de 23 de novembro de 1988 e dispositivos do Decreto-lei n. 221, de 28 de fevereiro de 1967 e dá outras providências. Disponível em: <http://www.planalto.gov.br/ccivil_03/_ato2007-2010/2009/Lei/L11959.htm>. Acesso em: 17 jun. 2014.

. Decreto n. 4.895, de 25 de novembro de 2003. Dispõe sobre a autorização de uso de espaços físicos de corpos d'água de domínio da União para fins de aqüicultura e dá outras providências. Disponível em: $<$ http://www.planalto.gov.br/ccivil_03/decreto/2003/D4895.htm>. Acesso em: 17 jun. 2014.

BRAZ, M.; NETTO, J. P. Economia política: uma introdução crítica. São Paulo: Cortez, 2011.

CAMPOS, A. C.; FERNANDES, E. A. Investimento direto estrangeiro e o desempenho das exportações brasileiras. Revista de Economia Política, São Paulo, v. 28, n. 3, 2008. Disponível em: <http://www.scielo.br/pdf/rep/v28n3/a08v28n3.pdf > . Acesso em: 21 jun. 2014.

CONAMA. Resolução n. 459, de 16 de outubro de 2013. Altera a Resolução n. 413, de 26 de junho de 2009, do Conselho Nacional do Meio Ambiente (Conama), que dispõe sobre o licenciamento ambiental da aquicultura e dá outras providências. Disponível em: $<$ http://www.mma.gov.br/port/conama/legiabre.cfm?codlegi=699 $>$. Acesso em: 27 jun. 2014.

. Resolução n. 413, de 26 de junho de 2009. Dispõe sobre o licenciamento ambiental da aquicultura e dá outras providências. Disponível em: $<$ http://www.mma.gov. br/port/conama/legiabre.cfm?codlegi=608> . Acesso em: 27 jun. 2014.

CARDOSO, E. S. Trabalho e pesca: apontamentos para investigação. Revista Pegada (eletrônica), v. 10, n. 2, 2009. Disponível em: <http://www4.fct.unesp.br/ceget/ PEGADA102/05eduardo1002.pdf > . Acesso em: 25 mar. 2010.

. Pescadores artesanais: natureza, território, movimento social. Tese (Doutorado em Geografia Física) - Universidade de São Paulo: São Paulo, 2001. Disponível em: <http://www.teses.usp.br/teses/disponiveis/8/8135/tde-14012003-160032/pt-br. php>. Acesso em: 19 jun. 2014.

CRIVELA, M. Reforma aquária já! Folha de S.Paulo, 26 maio 2013, caderno Opinião. Disponível em: <http://www1.folha.uol.com.br/opiniao/2013/05/1284953-marcelocrivella-reforma-aquaria-ja.shtml>. Acesso em: 2 jul. 2014.

FERNANDES, F. A revolução burguesa no Brasil: ensaios de interpretação sociológica. 5. ed. Rio de Janeiro: Globo, 2006. 
GONÇALVES, R. Governo Lula e o nacional desenvolvimentismo às avessas. In: Revista Sociedade Brasileira de Economia e Política, São Paulo, n. 31, 2012. Disponível em: <http://www.sep.org.br/revista/download?id=219>. Acesso em: 21 jun. 2014. INSTITUTO DE ESTUDOS PARA O DESENVOLVIMENTO INDUSTRIAL (IEDI). O investimento estrangeiro na economia brasileira e o investimento de empresas brasileiras no exterior. Disponível em: < http://iedi.org.br/admin/pdf/inv_estrang.pdf > Acesso em: 21 jun. 2014.

MANDEL, E. O capitalismo tardio. 2. ed. São Paulo: Nova Cultural, 1985.

MARX, K. O capital. 18. ed. Rio de Janeiro: Civilização Brasileira, 2001. v. I, livro 1. MÉSZÁROS, I. Para além do capital: rumo a uma teoria da transição. Tradução Paulo Cezar Castanheira e Sérgio Lessa. São Paulo: Boitempo, 2011.

MALAFAIA JÚNIOR, S. Estudos de inteligência de mercado. Pesquisa de mercado, informe do serviço brasileiro de apoio às micro e pequenas empresas. Brasília: Sebrae, 2010. Disponível em: $<$ http://201.2.114.147/bds/bds.nsf/9ABFB9037516E51E832578 81004C6E35/\$File/NT000455DA.pdf>. Acesso em: 21 jun. 2014.

MALVEZZI, R. Os ruralistas e o hidronegócio. Brasil de fato, 12 mar. 2012. Disponível em: <http://www.brasildefato.com.br/node/9022. Acesso em: 26 jun. 2014.

SANTOS, J. “Questão Social”: particularidades no Brasil. São Paulo: Cortez, 2012.

SILVA, M. das G. e. Questão ambiental e desenvolvimento sustentável: um desafio ético-político ao Serviço Social. São Paulo: Cortez, 2010. 